\title{
Prevalence of depressive symptoms in professionally active Polish people
}

\author{
Konopko $\mathrm{M}^{1}$, Swiecicki L1, Antosik-Wojcinska $\mathrm{A}^{2}$, Bienkowski $\mathrm{P}^{3}$, Bucior $\mathrm{E}^{1}$, Sienkiewicz- \\ Jarosz $\mathrm{H}^{1}$ \\ 1 1st Department of Neurology, ${ }^{2} 2$ nd Department of Psychiatry, Institute of Psychiatry and Neurology, Warsaw, Poland \\ ${ }^{3}$ Department of Psychiatry, Faculty of Medicine, Medical University of Warsaw, Poland \\ *Correspondence to: jarosz@ipin.edu.pl
}

Background: Depression and depressive symptoms are potential factors that affect the quality of life, the ability to work, work effectiveness, and may be also the cause of long-term sick leave. Depression has a negative impact on the overall health, because it worsens compliance, and promotes lack of adequate prevention and treatment of somatic diseases. The role of socioeconomic and demographic factors in depression as well as occupational risk factors is still the matter of debate.

Aims: To establish the prevalence of depression symptoms among professionally active people in Poland.

Methods: One thousand seven hundred ninety-five professionally active people completed structured questionnaire included items regarding socioeconomical status, general health, work-related problems (i.e. burnout symptoms) and Patient Health (PHQ-9) questionnaire (Konopko et al., 2018; Kroenke et al., 2002).

Results: The study group was representative according to place of living and profession (Table 1).

Mean age of participants was $35.3 \pm 11.62 \mathrm{yr}(23-65), 53.3 \%$ were men. People aged 30-39 accounted for $38.4 \%$ of the respondents, aged 40 to $49-30.2 \%$, and aged 50 to 59 $27.1 \%$.

Twenty five percent declared living in villages, $26.9 \%$ in towns ( $>5000$ inhabitants), and $38.0 \%$ in cities $(>200 \quad 000$ inhabitants). Fourty percent declared different levels of university education, and $47 \%$ higher education.

Table 1.

\begin{tabular}{|l|c|c|c|c|}
\hline \multicolumn{1}{|c|}{ Trade } & $\begin{array}{c}\text { Numbers in } \\
\text { population }\end{array}$ & $\mathbf{\%}$ & $\begin{array}{c}\text { Predicted } \\
\text { numer of } \\
\text { interviews }\end{array}$ & $\begin{array}{c}\text { Number of } \\
\text { finished } \\
\text { interviews }\end{array}$ \\
\hline Public administration & 644739 & $4,3 \%$ & 65 & $\mathbf{1 1 9}$ \\
\hline Construction & 872807 & $5,8 \%$ & 87 & $\mathbf{1 4 7}$ \\
\hline Education & 1152094 & $7,7 \%$ & 116 & $\mathbf{1 1 9}$ \\
\hline Tradel & 2299084 & $15,4 \%$ & 230 & $\mathbf{2 3 9}$ \\
\hline Other & 1362302 & $9,1 \%$ & 136 & $\mathbf{2 1 4}$ \\
\hline Healthcare & 865686 & $5,8 \%$ & 87 & $\mathbf{9 6}$ \\
\hline Manufacturing & 2671042 & $17,8 \%$ & 268 & $\mathbf{2 7 1}$ \\
\hline Mining and quarrying & 151251 & $1,0 \%$ & 15 & $\mathbf{7 3}$ \\
\hline Agriculture and forestry & 2390935 & $16,0 \%$ & 240 & $\mathbf{2 5 6}$ \\
\hline Service activities & 2554471 & $17,1 \%$ & 256 & $\mathbf{2 6 1}$ \\
\hline Total & 14964411 & $100,0 \%$ & 1500 & $\mathbf{1 7 9 5}$ \\
\hline & & & \\
\hline
\end{tabular}

\section{Conclusions:}

The prevalence of depression in Polish professionally active people is similar to the previously reported in other populations.

Self-reported lack of family support, feeling of loneliness, and work-related problems are important factors related to depression in this group.

References:

K. Kroenke, R.L. Spitzer, J. B. Williams, J. Gen. Intern. Med. 16 (2001) Konopko M, Jarosz W, Bienkowski P, Sienkiewicz-Jarosz H. MATEC Web of Conferences 247, 00065 (2018)
The prevalence of depressive symptoms (according to PHQ-9 results) was $32.1 \%: 2.7 \%$ for severe and moderately severe depression, $7.5 \%$ for moderate symptoms of depression, and $21.8 \%$ for mild depression, respectively.

The majority of the study group assessed their family relationships as good $(48.3 \%)$ and very good $(32.7 \%)$, and only $4.0 \%$ as very complicated and difficult.

The self-perceived loneliness is presented on Figure 1.

Depressive symptoms severity correlated with female gender, depression in medical history, self-perceived family support and subjective feeling of loneliness. People reporting depressive symptoms declared lower ability to continue their professional activity for the next two years and more frequently reported burnout symptoms.

We could not identify a single independent factor that could unambiguously predict the severity of depressive symptoms in the group of professionally active people.

The seven strongest correlating factors were: the sum of significant medical conditions, self-assessed family relationships, a subjective sense of loneliness, taking psychotropic medications, sleep disturbances, feeling irritable when discussing work-related topics, and a subjective feeling that the disease will prevent ones from doing work. These factors did not allow to explain more than $\underline{36 \%}$ of variability in the PHQ-9 score.

The model based on a wide spectrum of demographic and clinical variables explained no more than $40 \%$ of variability in the PHQ-9 score.

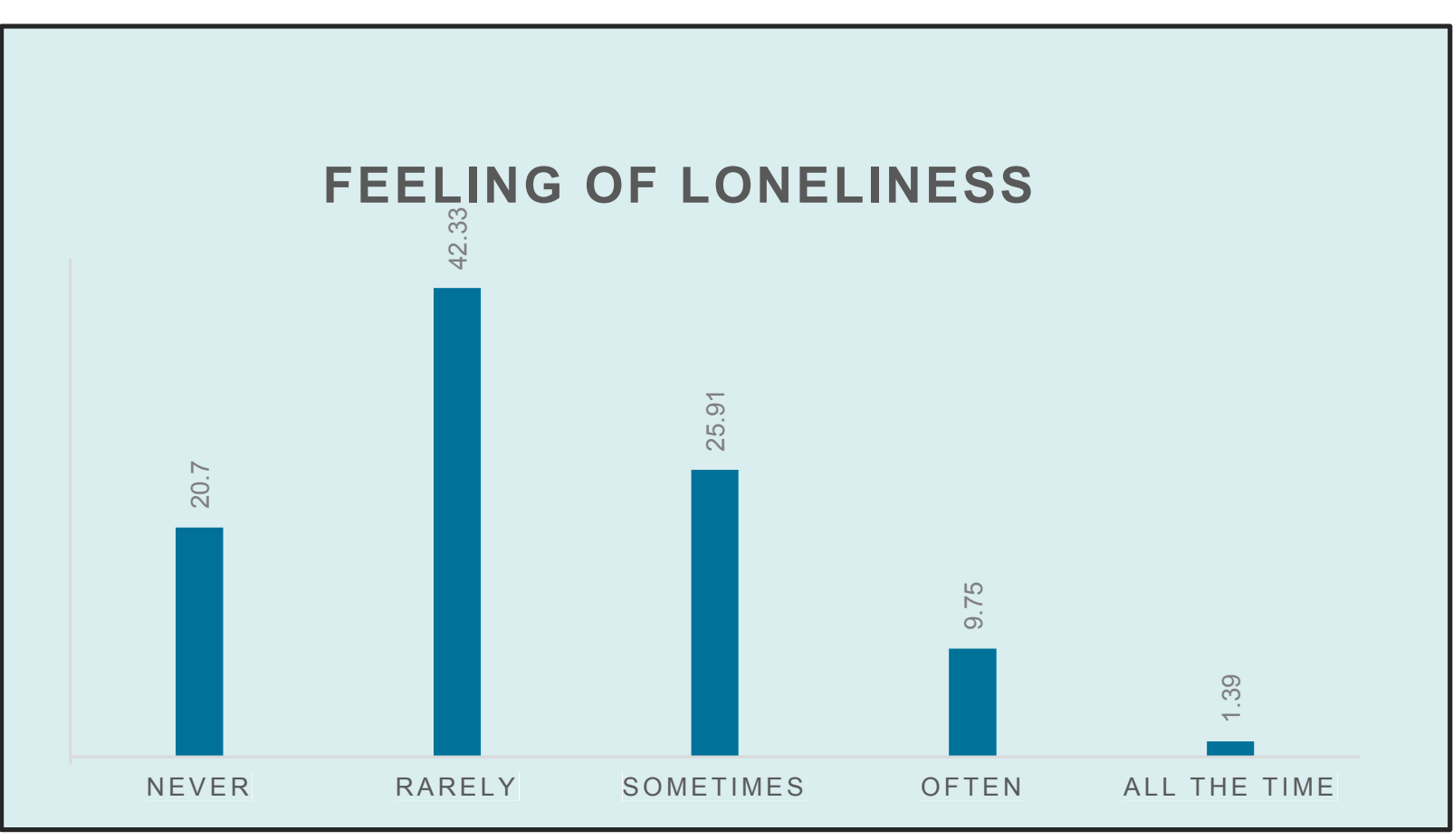

\section{Acknowledgment:}

Publication based on the results of the fourth stage of the multiannual program "Improving safety and working conditions ", financed in 2017-2019 in the field of research and development from the funds of the Ministry of Science and Higher Education/National Center for Research and Development. Program coordinator: Central Institute for Labor Protection National Research Institute. (PBiWP-IV/2017 Sub-contract No TP-48/2017/PW-PB project I.N.08). 